\title{
Utilização de um modelo de engajamento colaborativo na elaboração de instrumentos legais participativos
}

\author{
Jonas H. R. Paula ${ }^{1}$, Bárbara P. Caetano ${ }^{2}$, Melise M. V. de Paula ${ }^{1}$ \\ ${ }^{1}$ Programa de Pós-Graduação em Ciência e Tecnologia da Computação \\ Universidade Federal de Itajubá (UNIFEI) - Itajubá - MG - Brasil \\ ${ }^{2}$ Programa de Engenharia de Sistemas e Computação \\ Universidade Federal do Rio de Janeiro (UFRJ) - Rio de Janeiro - RJ - Brasil \\ \{jonashenrq, melise\} @unifei.edu.br, bpimentacaetano@cos.ufrj.br
}

\begin{abstract}
The City Statute is a Brazilian federal law that regulates urban policy across the country and requires that the legal instruments designed to organize the growth of cities be built in a participatory manner. The actors involved in this process need a collaborative space to expose their ideas to create opportunities for participation. However, the lack of engagement of these actors is often a factor that compromises this type of activity. This article presents the preliminary results of using a collaborative engagement model to mitigate this problem, using process mapping to identify the flow of activities.
\end{abstract}

Resumo. O Estatuto da Cidade é uma lei federal brasileira que regulamenta a política urbana em todo o país e determina que os instrumentos legais elaborados para organizar o crescimento das cidades sejam construidos de forma participativa. Os atores envolvidos nesse processo necessitam de um espaço colaborativo para expor suas ideias de forma a criar oportunidades de participação. Contudo, a falta de engajamento destes atores é, frequentemente, um fator que compromete muito esse tipo de atividade. Este artigo apresenta os resultados preliminares de um estudo cujo objetivo é o uso de um modelo de engajamento colaborativo para mitigar esse problema. Nesta etapa do trabalho, foi realizado o mapeamento das atividades relacionadas à elaboração de um dos instrumentos instituído pelo EC.

\section{Introdução}

O Estatuto da Cidade (EC) regulamenta os artigos 182 e 183 da Constituição Federal e estabelece diretrizes gerais da política urbana [BRASIL 2001] determinando como deve ser feita a política urbana em todo o país. A aplicação do EC representa um desafio para a administração municipal, um dos motivos é a exigência da participação popular na gestão da política urbana como forma de assegurar a equidade os direitos dos cidadãos [Camargo e Moraes 2015].

O EC utiliza instrumentos legais para regulamentar estes artigos, na esfera municipal, por exemplo, são definidos diversos planos como o plano diretor, o plano de zoneamento ambiental, plano de saneamento, plano de desenvolvimento econômico e social, plano de mobilidade e o orçamento participativo. Um dos objetivos comuns a todos esses instrumentos é assegurar melhores condições de vida, de forma participativa e democrática, para a toda população [BRASIL 2001]. 
Para garantir essa participação, foram criadas algumas regras no processo de elaboração destes instrumentos que estabelece a autonomia do poder público municipal para a construção do plano, mas também o dever em promover audiências públicas, debates com os cidadãos, fazer a publicidade dos documentos e informações produzidas ao longo do desenvolvimento e, por fim, promover o acesso a qualquer pessoa aos documentos e informações produzidas [Brasil 2001].

Para Carvalho e Braga (2001), muitas vezes, a falta de preparo técnico e institucional dos gestores pode potencializar as dúvidas em relação às questões de quais instrumentos utilizar e como garantir a participação popular. A construção de processos com um alto grau participativo requer um certo grau de planejamento e mobilização política. Para Pinheiro (2014), a ausência da participação dos cidadãos é um dos maiores indicativos de insucesso de planos, programas e projetos.

Araujo et al. (2012) afirmam que um dos aspectos que podem promover a participação cidadã é a colaboração entre os participantes. Porém, os cidadãos e especialistas envolvidos nos projetos possuem agendas conflitantes e demandas divergentes sobre as escolhas públicas, sendo necessário um espaço colaborativo para que os envolvidos possam apresentar seu ponto de vista [Weise et al. 2017]. Entretanto os cidadãos e especialistas podem não se engajar nesses espaços colaborativos. Desta forma, não basta somente a intervenção de tecnologias colaborativas nos processos, é necessário que os atores responsáveis estejam engajados no uso dessas tecnologias.

Diante disto, este trabalho faz parte de uma pesquisa em andamento que propõe o uso do Modelo de Engajamento Colaborativo (MEC) para mitigar este problema, focando no processo de mobilização e participação quando da elaboração desses instrumentos. $\mathrm{O}$ MEC foi proposto em Oliveira et al. (2019) e Oliveira (2020) tendo como objetivo propor uma abordagem para promover a participação através da combinação do Modelo $3 \mathrm{C}$ de Colaboração com o ciclo de engajamento de O'Brien e Toms (2008).

Esta pesquisa está sendo desenvolvida em parceria com o Núcleo Estratégico Interdisciplinar de Resiliência Urbana (NEIRU) que é um núcleo de pesquisa e extensão vinculado a Universidade Federal de Itajubá. Um dos serviços prestados por esse grupo é a revisão e/ou elaboração dos instrumentos legais instituídos no EC, sendo dois destes instrumentos o plano diretor e plano de meio ambiente.

Especificamente neste artigo, como resultado parcial, será apresentado o mapeamento dos processos executados na estratégia de mobilização e participação nos projetos realizados pelo NEIRU. A proposta desse mapeamento é representar as atividades realizadas de acordo com o MEC combinando duas perspectivas: colaboração e engajamento. O objetivo deste artigo é descrever o resultado deste mapeamento e da utilização do MEC, considerando o cenário de elaboração planos diretores, saneamento e meio ambiente.

O mapeamento foi necessário pois um dos elementos que caracterizam o MEC é a necessidade de coordenar as atividades do processo colaborativo sob a perspectiva do ciclo de engajamento. Assim, para formalizar o fluxo de atividades e os atores responsáveis, foi realizado o mapeamento representando as atividades com a notação Business Process Model and Notation (BPMN). 


\section{Modelo de Engajamento Colaborativo}

O Modelo de Engajamento Colaborativo foi proposto inicialmente por Oliveira et al. (2019), neste modelo os autores propõem a utilização do Modelo 3C de Colaboração para estruturar as atividades de coordenação, comunicação e cooperação combinando com as etapas do ciclo de engajamento proposto por O'Brien e Toms (2008).

O Modelo $3 \mathrm{C}$ de Colaboração é composto por três pilares: comunicação, coordenação e cooperação. Para colaborar, os indivíduos devem trocar informações (comunicar), organizar-se (coordenar) e operar em conjunto em um ambiente compartilhado (cooperar) [Fuks et al. 2011]. Em relação ao engajamento, O'Brien e Toms (2008) o define como um estado psicológico permanente que ocorre em vários estágios e intensidades. Os autores estabeleceram o processo de engajamento em quatro etapas: ponto inicial de engajamento, estado de engajamento, desengajamento e reengajamento.

Considerando os dois modelos, Oliveira et al. (2019) defendem que: para a coordenação, todas as atividades devem ser estruturadas em um fluxo levando em consideração as etapas do engajamento descritas por O'Brien et al. (2008), ou seja, observando o ponto inicial do engajamento, o engajamento, desengajamento e reengajamento.

Para a comunicação, é importante que seja garantida a transparência do processo e que as informações estejam dispostas de forma clara e amigável. Considerando a cooperação como o ato de operar/agir/atuar juntamente com alguém para atingir um determinado objetivo, os autores propõem o desenvolvimento de artefatos que podem ser considerados como um ambiente, ainda que virtual, que permite a operacionalização dessa ação em conjunto.

O ponto inicial de engajamento corresponde ao momento em que o usuário conhece o artefato e têm acesso às informações sobre o processo colaborativo que será realizado. Portanto, a apresentação dos artefatos construídos e a comunicação eficiente podem estimular o interesse dos usuários. As estratégias utilizadas para comunicação devem ser compatíveis com o perfil dos atores que deverão fazer parte dessa atividade. Para o engajamento, é essencial que todos tenham acesso às informações e oportunidades para comunicação.

Para entrar no estado de engajamento, o artefato deve manter a atenção do participante por meio de estímulos às emoções positivas. Desta forma, a usabilidade é um aspecto importante a ser considerado, a atratividade da interface e satisfação do usuário são essenciais. A cooperação entra em destaque nessa etapa, pessoas engajadas são mais propensas à cooperação.

Após o uso do artefato, os usuários podem perder o interesse em continuar por conta de emoções negativas resultantes da experiência, como dificuldade de uso ou distrações por fatores externos, essa fase é chamada de desengajamento. Para que ocorra o reengajamento, deve ser realizado um esforço para recuperar o sentimento positivo dos atores envolvidos e manter a motivação e o interesse.

\section{Resultados Preliminares}

Para a elaboração de alguns dos instrumentos instituídos pelo EC, um dos produtos que devem ser entregues é o plano de participação social cujo objetivo é descrever de que maneira a população local terá acesso às informações e oportunidades para participar do 
processo de construção do instrumento. Nos planos elaborados pelo NEIRU, foi proposta uma estratégia para mobilização e participação social que vem sendo refinada em quatro execuções de planos diretores em municípios diferentes, 2 planos de saneamento e 1 plano de meio ambiente. $O$ objetivo dessa estratégia é promover a colaboração entre os diferentes atores envolvidos. Portanto, o primeiro aspecto discutido nessa seção é a descrição desses atores.

Durante o processo de elaboração ou revisão dos instrumentos do EC, foram identificados diferentes atores que possuem atribuições específicas: equipe executora (EE): composta por técnicos (podendo ser terceirizados) que devem dar orientações e conduzir as atividades do processo de elaboração ou revisão dos instrumentos legais; núcleo gestor (NG): é um grupo de pessoas responsável por assessorar e fornecer informações para a equipe executora e assegurar a comunicação com o poder executivo e os atores da sociedade civil, podendo ser considerados os representantes da população. $O$ NG deve ser, obrigatoriamente, representativo, ou seja, os diversos segmentos da sociedade e lideranças do município devem ser representados como, por exemplo, empresas privadas, ONGs, movimentos sociais, sindicatos rurais e/ou comercias, dentre outros; grupo trabalho executivo (GTE): é um grupo composto por representantes da prefeitura, definidos mediante a interação do Poder Público Municipal com o agente técnico. Suas contribuições consistem basicamente em assegurar que a elaboração do plano esteja de acordo com os fins definidos pelo contrato estabelecido; influenciadores: são pessoas consideradas socialmente influentes na cidade que tenham um alcance significativo na população. Embora inclua-se os influenciadores digitais, no processo, esses termos não são sinônimos, os influenciadores podem ajudar na motivação usando outros recursos que não as redes sociais. A atribuição dos influenciadores no processo é auxiliar na divulgação das atividades para a população visando atingir um maior número de pessoas e os cidadãos que têm o direito e o dever de participar desse processo de construção do instrumento uma vez que as leis estabelecidas interferem diretamente no bem estar dessas pessoas.

Tendo mapeado os atores e seus papéis, é necessário definir quais atividades caracterizam o processo definido a partir da estratégia elaborada. $\mathrm{O}$ modelo resultante desse mapeamento está apresentado na Figura 1. Como o processo é extenso e com recursividade, o modelo está disponível para consulta através do link https://1drv.ms/u/s!AlcTyCQvcZHllMdFiZ05VitLGUHpDw?e=LLfbZ3.

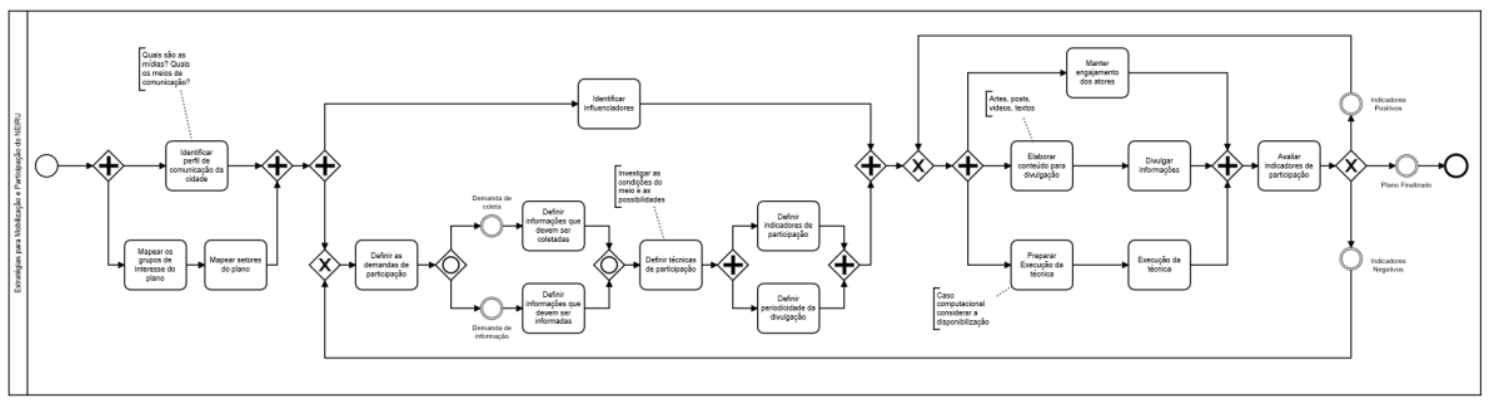

Figura 1 - Mapeamento BPMN do Processo de Mobilização e Participação do NEIRU

No início do fluxo, são realizadas, paralelamente, três atividades: identificação do perfil de comunicação da cidade, mapeamento dos atores locais e de setores. $\mathrm{Na}$ identificação do perfil, devem ser mapeados quais são os principais canais de mídias locais e meios de comunicação utilizados pela população. Esses canais são fortemente 
dependentes do ambiente ou cidade podendo envolver rádio, televisão, divulgação através de cartazes, panfletos, carros de som dentre outros.

No mapeamento dos atores locais, devem ser identificados quais grupos ou entidades representativas da sociedade deverão ser mobilizados e considerados nas análises durante o processo. No mapeamento de setores, será realizada a setorização da cidade. Os setores representam divisões do espaço da área urbana e rural da cidade sendo identificados considerando mapas fornecidos pela prefeitura e disponíveis no IBGE além de informações sobre o valor dos imóveis e do nível socioeconômico dos moradores. Tanto a setorização, quanto o mapeamento de atores locais, são atividades importantes pois dependendo das especificidades desses atores e setores, deverão ser definidas estratégias de mobilização social específicas e novas formas de comunicação e compartilhamento de espaços.

Seguindo o fluxo, são executados paralelamente a identificação dos influenciadores e a identificação das demandas de participação. Na identificação dos influenciadores, são realizadas reuniões com o NG para facilitar a identificação de pessoas socialmente influentes da cidade que poderão auxiliar na divulgação das atividades do plano e mobilização da população. Para complementar essa análise, é realizada uma investigação nas redes sociais e utilizadas ferramentas específicas para encontrar os perfis mais influentes digitalmente. Vale destacar que esses influenciadores não se restringem ao ambiente virtual. Um dirigente religioso, por exemplo, pode ser um desses influenciadores e ter um papel importante na motivação da população.

$\mathrm{Na}$ identificação das demandas de participação, são definidas as seguintes atividades: definir informações que devem ser apresentadas ou coletadas [6], definir a técnica de participação, definir indicadores de participação e a periodicidade da divulgação. $O$ termo demandas de participação representa os marcos do processo em que a participação da população é necessária para que alguma atividade do processo seja realizada. Além disso, em alguns casos, essas demandas podem ser contínuas e fazer parte de todo processo. Basicamente, pode-se considerar que existem dois tipos de demandas: disponibilizar a informação aos atores envolvidos e coletar informação desses atores. No primeiro caso, o objetivo é tornar a informação disponível à população. Além de ser informada, a população precisa conhecer o processo. No segundo caso, a participação é necessária para que seja possível conhecer a opinião da população a respeito dos diferentes temas discutidos.

Nos planos realizados pelo NEIRU, a população deve ser informada tão logo inicia a execução sobre quais são as etapas, o cronograma, os produtos que deverão ser entregues e quais canais de comunicação e participação estarão disponíveis. Esse é um exemplo de demanda de disponibilização da informação. No NEIRU, a cada novo plano, são realizados dois tipos de eventos: Oficinas estratégicas e o Seminário da Cidade. As oficinas estratégicas são realizadas com o NG, GTE e os influenciadores. O principal objetivo dessas oficinas é mobilizar e informar esses atores. Já o Seminário da Cidade é realizado para a população, dependendo das especificidades do local, esses seminários podem acontecer em escolas, associações de bairro ou comerciais, por exemplo. Contudo, durante toda a execução do plano, as informações sobre o processo são divulgadas, não somente nesses eventos.

Já na demanda de coleta, é necessário que a população, seja através de seus representantes ou diretamente, tenha oportunidade de cooperar efetivamente com a 
execução do plano dando sua opinião tanto a respeito dos problemas da cidade quanto das oportunidades de melhorias. No plano diretor, por exemplo, um dos produtos entregues é o diagnostico participativo que deve ser elaborado combinando o diagnóstico técnico, elaborado pelos especialistas nas áreas analisadas, com a opinião da população. Esse é um exemplo de uma demanda de coleta que acontece em um momento específico. Contudo, durante toda a execução do plano, a população pode usar os canais de participação definidos.

As atividades necessárias para definição das demandas de participação dependem fortemente do perfil de comunicação da cidade e dos recursos da administração pública e iniciam com a identificação das informações que devem ser apresentadas ou coletadas. Em seguida, deve definida técnica utilizada para viabilizar a participação. Se a demanda for informação/divulgação, devem ser definidas quais canais de divulgação serão utilizados. Dentre os canais possíveis, pode-se citar rádio, televisão, divulgação em igrejas, redes sociais e aplicativo de mensagens. Por outro lado, se a demanda for para a coleta de informação, podem ser utilizados recursos como: pesquisas de opinião em formulários ou ferramentas específicas, redes sociais dedicadas à discussão de problemas sociais e questões relacionadas à cidade e a vida em sociedade e outras abordagens que permitam que a população se expresse.

Nos planos realizados pelo NEIRU em 2020, devido à pandemia e a necessidade de isolamento, as técnicas utilizadas para atender às demandas identificadas foram definidas em ambientes virtuais. As oficinas foram realizadas no Google Meet e o Seminário foi transmitido ao vivo no YouTube. A coleta de opinião foi realizada através de um aplicativo, o Opina Aí, e a população foi fortemente estimulada a utilizar o SOPA, uma rede social proposta por Caetano, Paula e Souza (2020) com o objetivo de proporcionar um ambiente estruturado para discussão de questões relacionadas aos instrumentos. Todos os recursos disponibilizados foram amplamente divulgados com o apoio dos influenciadores, utilizando as redes sociais e outros canais de comunicação identificados.

Em seguida, devem definidos indicadores para avaliar as estratégias de participação. Esses indicadores são determinados através de medidas que indiquem o sucesso ou não da estratégia e são importantes para o aprimoramento das técnicas na tentativa de aumentar o engajamento. Em paralelo à definição dos indicadores, é realizada a definição de periodicidade de divulgação para as demandas considerando aspectos como: as datas de possíveis eventos, período para coleta de dados, frequência de divulgação e a escolha de horários de forma a alcançar os diferentes grupos da cidade.

A partir desse ponto do fluxo, as estratégias definidas começam a ser efetivamente executadas formando o ciclo de divulgação e coleta de opinião. A divulgação se refere às demandas de participação para a divulgação de informação com as seguintes atividades: manter engajamento dos atores, elaborar os conteúdos para divulgação e divulgar as informações. $O$ contato com os atores é a forma de manter o engajamento e a colaboração desses agentes de forma contínua, o contato deve mantê-los motivados. $\mathrm{O}$ conteúdo para divulgação depende das técnicas definidas para participação. Depois de elaborado o conteúdo, a informação é efetivamente divulgada considerando os canais identificados. Essas atividades se repetem durante todo o processo.

Para a coleta de opinião é necessário preparar a técnica e executar a técnica definida A preparação envolve estabelecer os requisitos necessários para a execução. Em 
seguida, a participação ocorre de fato na execução da técnica. Os dados coletados devem ser disponibilizados para análise pelos diversos agentes envolvidos. Por fim, é necessário avaliar os indicadores de participação. Caso os indicadores sejam positivos, o ciclo de divulgação e opinião continuam. Caso sejam negativos, a estratégia deve ser revista. $\mathrm{O}$ processo se encerra quando for finalizada a criação/revisão do plano.

Este mapeamento foi elaborado com o objetivo de contemplar a coordenação do MEC, considerando o ciclo do engajamento sob a perspectiva da população. Levando em conta as etapas do ciclo de engajamento definidas no MEC, o ponto inicial de engajamento pode ser observado em todas as atividades que envolvem, de alguma forma, a mobilização, considerando, por exemplo, apresentações de informações, definição e preparação das técnicas e divulgação das demandas. Já a etapa de engajamento, começa na execução da técnica, tendo em vista que nesta atividade inicia-se o contato com a população através de oficinas, seminários e ferramentas colaborativas destinadas para discussão das questões relacionadas aos planos ou para coleta de opinião. Durante o processo, quando o indicador de uma determinada demanda é considerado negativo, é necessário fazer uma análise, pois o índice negativo pode representar um possível desinteresse da população, entrando assim na etapa de desengajamento.

Em relação aos outros aspectos do MEC para este processo, no aspecto da cooperação, deve-se manter um ambiente acessível e agradável para a população, para ambientes virtuais, as ferramentas devem possuir uma boa usabilidade e disponível para acesso público em todo o processo. Referente a comunicação, esta deve ser clara, transparente, convidativa, compreensível por todos e deve garantir a possibilidade de o cidadão emitir sua opinião.

O mapeamento BPMN do processo de mobilização e participação foi validado seguindo a estratégia de validação apresentada em Hochleitner and Oppl (2018). Nesta estratégia, a validação consiste em verificar se o modelo retrata a realidade do processo do negócio e avalia se o modelo utiliza a sintaxe correta da linguagem de modelagem escolhida.

O modelo foi apresentado aos especialistas em participação cidadã e foi constatado que o mapeamento representa a realidade do que executado pelo NEIRU. Para validar se o modelo utiliza a sintaxe correta da linguagem, foi apresentado o contexto do negócio e a modelagem para um especialista em modelagem de processos e verificou-se que foi utilizada a sintaxe correta da notação BPMN.

\section{Próximas Etapas}

Como este trabalho considerou apenas a perspectiva da participação do cidadão no processo, o próximo passo é avaliar sobre a perspectiva da colaboração entre a equipe executora, núcleo gestor e influenciadores. Para isso será realizada uma análise qualitativa das atividades que envolvem a colaboração entre esses atores, através de entrevistas com os responsáveis pelas tarefas, com foco nas dificuldades e potencialidades de comunicação, coordenação, cooperação de forma a aumentar o engajamento.

Após o levamento das dificuldades e potencialidades, serão investigadas quais tecnologias colaborativas poderão ser implementadas para dar suporte a colaboração. Também serão instanciadas novas versões do MEC para a representação do contexto com a perspectiva dos outros atores, de forma a facilitar concepção e elaboração de artefatos que possam solucionar estas dificuldades para todos os envolvidos. Em relação às 
questões de pesquisa a ser definida, ainda estão sendo investigadas formas de validar se houve ampliação do engajamento após a utilização do Modelo de Engajamento Colaborativo, considerando as intervenções de tecnologias colaborativas.

\section{Referências}

Araujo, R. M. De, Cappelli, C., Diirr, B., Engiel, P. and Tavares, R. L. (2012). Democracia eletrônica. Sistemas Colaborativos. Elsevier. p. 110-121.

Brasil (2001). Lei No 10.257, de 10 de jul. 2001. Regulamenta os arts. 182 e 183 da Constituição Federal, estabelece diretrizes gerais da política urbana e dá outras providências. Diário Oficial, Brasília, 11 jul. 2001.

Caetano, B., Paula, M. and De Souza, J. (2020). SoPa: A Social Media for a Participatory Society. IEEE Access, v. 8, p. 70627-70639.

Camargo, L. T. and Moraes, S. T. (2015). Plano diretor participativo: os desafios da gestão democrática da política urbana no município de Joinville (SC). Revista Brasileira de Gestão e Desenvolvimento Regional; v. 11, n. 2

Carvalho, P. F. De and Braga, R. (2001). Perspectivas de gestão ambiental em cidades médias. Rio Claro: Laboratório de Planejamento Municipal.

Fuks, H., Raposo, A. B., Gerosa, M. A., et al. (2011). Teorias e modelos de colaboração. Sistemas colaborativos, p. 16-33.

Hochleitner, F. and Oppl, S. (2018). Validation of Business Process Models through Interactively Enacted Simulation. In Proceedings of the 10th International Conference on Subject-Oriented Business Process Management - S-BPM One '18. . ACM Press.

O'Brien, H. L. and Toms, E. G. (2008). What is user engagement? A conceptual framework for defining user engagement with technology. Journal of the American Society for Information Science and Technology, v. 59, n. 6, p. 938-955.

Oliveira, K., Paula, M., E. R. G. Alves, G., et al. (2019). Aplicação de um modelo de colaboração em um contexto de participação social. In Anais do Simpósio Brasileiro de Sistemas Colaborativos. Sociedade Brasileira de Computação - SBC.

Oliveira, Kayque W. R. (2020). Participando com jogos: uma análise da gamificação como intervenção em pesquisas de opinião. 2020. 156 f. Dissertação (Doutorado) Curso de Programa de Pós-graduação em Ciência e Tecnologia da Computação, Universidade Federal de Itajubá, Itajubá.

Pinheiro, O. M. (2014). Plano diretor e gestão urbana. 3. ed. Florianópolis: CAPES : UAB.

Weise, S., Coulton, P. and Chiasson, M. (2017). Designing in between Local Government and the Public - Using Institutional Analysis in Interventions on Civic Infrastructures. Computer Supported Cooperative Work (CSCW), v. 26, n. 4-6, p. 927-958. 